\title{
Artigos
}

Sílvia Adriana Rodrigues 2

\section{Mudanças e persistências na formação para docência em creches e pré-escolas ${ }^{1}$}

Resumo: As reflexões trazidas no presente artigo têm como intento se unir ao debate sobre identidade e profissionalidade dos docentes da educação infantil, tendo como pressuposto que embora a Educação Infantil tenha sido reconhecida como parte da educação básica e diretrizes político-pedagógicas já foram elaboradas considerando a especificidade desse nível de ensino, o cotidiano em que tais proposições deveriam ganhar materialidade, em alguns contextos, ainda não reflete estes avanços, em grande medida, porque ainda persistem percepções equivocadas do que é ser professor de crianças pequenas. Dessa forma, são aqui retomadas algumas discussões sobre crenças e valores que foram sendo associados sócio historicamente à profissão que se ocupa de educar e cuidar crianças pequenas e que ainda muito interferem no que se entende sobre ser e estar na docência na Educação Infantil; tal esforço se dá no sentido de contribuir para o necessário movimento de reelaboração do imaginário social e reconhecimento desta como atividade profissional qualificada.

Palavras-chave: Docência na Educação Infantil. Formação profissional. Identidade profissional.

\section{Changes and persistences in training for nursery and preschool teaching}

Abstract: The reflections brought in the present article are intended to join the debate on the identity and professionalism of teachers of early childhood education, assuming that although Early Childhood Education has been recognized as part of basic education and political-pedagogical guidelines have already been elaborated considering the specificity of this level of education, the daily life which such propositions should gain materiality in some contexts still does not reflect these advances, largely because misperceptions about what it is to be a teacher of young children still persist.In this way, some discussions about beliefs and values that have been associated sociohistorically with the profession that deals with educating and caring for children and that still much interfere in what is understood about being and being in the teaching in the early education, in the sense of contributing for a reelaboration of the social imaginary and recognition of this as qualified professional activity.

Keywords: Teaching in Early Childhood Education. Professional qualification. Professional identity.

\footnotetext{
' Esse artigo é um substrato da discussão teórica apresentada em tese de doutoramento.

${ }^{2}$ Doutora em Educação pela Universidade Estadual Paulista Júlio de Mesquita Filho. Professora Adjunta na Universidade Federal do Mato Grosso do Sul (UFMS). Líder do Grupo de Estudos e Pesquisas sobre Infâncias e Educação Infantil (GEPIEl - CPAN). E-mail:
} silvia.rodrigues@ufms.br 


\title{
Primeiras palavras
}

\author{
Não nasci, porém, marcado para ser um professor assim. Vim me tornando desta \\ forma no corpo das tramas, na reflexão sobre a ação, na observação atenta a outras \\ práticas ou à prática de outros sujeitos, na leitura persistente, crítica, de textos teóricos, \\ não importa se com eles estava de acordo ou não. É impossível ensaiarmos estar sendo \\ deste modo sem uma abertura crítica aos diferentes e às diferenças, com quem e com \\ que é sempre provável aprender. \\ $[\ldots]$ \\ Ninguém nasce feito. Vamos nos fazendo aos poucos na prática social de que tomamos \\ parte (FREIRE, P., 1993a, p. 80, grifos no original).
}

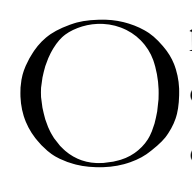
pressuposto freireano de construção da identidade profissional para a docência e a afirmação dela ao longo do exercício da profissão de ensinar é tomado como ponto de partida para empreender a presente discussão; pois assim como afirma o pensador recifence trazido na epígrafe, acredito que ser professor não é simplesmente questão de vocação ou dom, como se tem muitas vezes afirmado no senso comum, por outro lado creio que é necessário preparo e compromisso acadêmico, político e social para tal.

É certo que é preciso um mínimo de identificação com a profissão, mas penso que os saberes e fazeres dela, que permitirão ações pedagógicas de cunho profissional (ou seja, intencional e não intuitivos), são construídos e reconstruídos no processo de formação inicial e no exercício cotidiano da função, marcando, assim, a inesgotabilidade da formação. Neste sentido considero a epígrafe deveras oportuna, uma vez que conduz ainda a reflexão de que a profissionalidade docente se constrói na práxis cotidiana.

Cabe deixar claro que, sobre a formação para a docência de forma geral, tomo-a como o “[...] processo de apropriação e construção de formas de pensar, sentir, agir em situações de ensino e atribuir significados a seus componentes, segundo uma matriz ideológica que se constitui social e historicamente" (OLIVEIRA; FERREIRA; BARROS, 2011, p. 6), que se realiza de forma complexa ao longo do desenvolvimento pessoal e profissional e que serve de elemento norteador para a tomada de decisões sobre esta ou aquela forma de organizar o ensino e mediar à aprendizagem.

Corrêa e Fernandes (2014, p. 277) afirmam que a formação não pode ser encarada como “[...] sinônimo de fazer cursos e sim conhecer, transformar a partir de inúmeras metodologias pessoais e coletivas que farão parte de sua formação. Dentre tais metodologias, podem ser consideradas a prática da leitura, a experimentação, o trabalho colaborativo e a reflexão pessoal regular". Proença (2009, p. 15), complementarmente a estes apontamentos, indica que "[...] formar-se é constituir-se, completar-se nos estudos, nas técnicas necessárias a seu ofício, educar-se, criar-se [...] é buscar a própria identidade, como sujeito e membro de um grupo de professores [...]".

Importante esclarecer que a identidade é aqui entendida como papéis (determinados e em determinação) a serem desempenhados em espaços específicos, que se traduzem em condutas, valores e posturas assumidos pelo sujeito social; implica, ainda, a construção do sentimento de pertencimento social a um determinado grupo, que se dá pelas vias de reconhecimento e identificação externa (dos membros do 
grupo e não membros) e interna (de si mesmo como parte constituinte do grupo); e também de diferenciação (afirmação do grupo em relação a outros demais grupos).

Nas palavras de Gatti (1996, p. 85):

A identidade não é somente constructo de origem idiossincrática, mas fruto das interações sociais complexas nas sociedades contemporâneas e expressão sociopsicológica que interage nas aprendizagens, nas formas cognitivas e ações dos seres humanos. Ela define um modo de ser no mundo, num dado momento, numa dada cultura, numa história (destaque no original).

Dessa forma, especificamente sobre a identidade profissional, cabe o apontamento de que ela não é dada ou adquirida, não é uma propriedade, ou um produto, é um espaço de construção da maneira de ser e estar na profissão e desta forma não é imutável, externa ou individual, mas historicamente construída no âmbito das relações interpessoais por um grupo de sujeitos socialmente situados (NÓVOA, 1992; PIMENTA, 1999). A identidade docente então "[r]efere-se a um conjunto de características, experiências e posições de sujeito atribuídas (e auto atribuídas) por diferentes discursos e agentes sociais no exercício de suas funções [...]" (GARCIA, 2010, p. 1); assim, pressupõe a adoção de crenças, valores e atitudes que permitem, então, assumir o ser professor, perceber-se e afirmar-se professor e ainda ser reconhecido socialmente como tal.

No que diz respeito à identidade docente para atuação na Educação Infantil (creche e préescola) se faz importante retomar as crenças e valores que foram sendo associados sócio historicamente à profissão que se ocupa de cuidar/educar crianças bem pequenas e que ainda muito interferem no que se entende ser e estar na docência, especificamente na Educação Infantil (creches e pré-escolas) e que nos ajudam a entender de forma mais clara o que podem ser considerados avanços, persistências ou resistências em termos de discursos e práticas sobre a atenção educacional para a pequena infância.

\section{Papéis femininos e o exercício da docência junto às crianças pequenas}

Em se tratando especificamente da docência na Educação Infantil, mais que em outros níveis, esta é uma profissão acentuadamente exercida por mulheres, de forma histórica e socialmente determinada, associada à não necessidade de qualificação para seu exercício, ao baixo status profissional e, consequentemente, a baixos salários; também marcada historicamente por uma diversidade de concepções e associações com outras tarefas que, por consequência, se traduz em múltiplas denominações (AQUINO, 2010; CERISARA, 2002).

Relacionado ao caminho da profissionalização da professora da Educação Infantil, Nogueira (2008) discute que estas profissionais, ao longo desse processo, se deparam com três grandes e importantes questões: a primeira é o fato de ter escolhido exercer o magistério, uma profissão desvalorizada socialmente e academicamente, com o desafio de garantir (ou conquistar) seu valor e função intelectual. A segunda está em realizar um trabalho considerado "menor", de pouco valor, "de mulheres" no sentido pejorativo, assumindo a tarefa de militar contra o histórico processo de dominação e aviltação exercido sobre o que é essencialmente feminino. E, terceiro, encarar uma tarefa profissional - de se 
ocupar da educação e cuidado de crianças - entendida como "tarefa simples", quando de fato ela não é, e evidenciar dentro e fora das instituições de educação coletiva este fato.

Nessa perspectiva, questiona-se, quem é, e qual o perfil do profissional que deve se ocupar da educação e cuidados da criança pequena? Serão as mulheres? As mães? As tias? As pajens ou as educadoras? Que formação e saberes específicos são necessários à ação pedagógica intencional em espaços coletivos de educação da criança pequena? Como formar profissionais docentes para atender à demanda específica da creche? Tais questionamentos se assentam na crença de que os maiores passos para o delineamento do perfil adequado aos "atores educativos profissionais"2 se dão no processo formativo destes, e ainda que a formação profissional se configure num dos pontos essenciais de estruturação e implementação dos "rumos” da educação da pequena infância.

De forma similar, tencionando a questão, Ostetto (1997, p. 13) já perguntava:

[...] quem é o profissional de educação infantil? Pajem, babá, atendente, monitor, recreacionista, auxiliar de desenvolvimento infantil, professor, outra coisa... Quem é? Este questionamento, que chamei de crucial, não se refere somente a uma denominação, mas diz respeito ao perfil de um profissional que, por muito tempo, esteve "misturado" na própria "indefinição" do seu campo de atuação: casa, escola, nem isto, nem aquilo... (destaques no original).

Sobre a questão da profissionalização para atuação especificamente na Educação Infantil, Guimarães et al. (2009, p. 2.649) afirmam que o papel deste(a) profissional está “[...] intrinsecamente ligado à história da mulher em nossa sociedade e ao trabalho voluntário, uma vez que bastava possuir as qualidades maternas para desempenhar o papel de cuidar das crianças, principalmente nas creches”.

É atual a equivocada suposição (fortemente arraigada) de que as mulheres (quase que exclusivamente) devem assumir a responsabilidade básica pela educação e cuidado das crianças pequenas; também é esta razão para a ideia muito presente, tanto nos espaços de formação quanto de atuação, de que ao profissional da educação infantil ${ }^{3}$, especialmente na creche, é preciso mais "sentimento materno" (ou vocação para lidar com crianças) do que formação profissional, uma vez que quanto menor a criança, mais simples e feminino é considerado o trabalho a ser desempenhado. Campos (1999, p. 131) já apontava que "[...] confirma-se por toda a parte a regra que estabelece que quanto menor a criança a se educar, menor o salário e o prestígio profissional de seu educador e menos exigente o padrão de sua formação prévia".

Louro (1997) aponta que a carreira do magistério foi uma das grandes possibilidades encontradas pelas mulheres para conquistar o espaço público. A incursão nas escolas normais em meados do século XX se dá, basicamente, pelas mudanças nos contornos econômicos ocorridas na sociedade da época que fizeram com que os homens - até então únicos a ocuparem as funções responsáveis pela educação formal - se desinteressassem pela carreira do magistério e se voltassem para atividades profissionais mais rentáveis econômica e socialmente, desencadeando, assim, o processo de feminização da atividade profissional docente.

A mesma autora ainda aponta que esse processo não se deu sem resistências ou críticas; o que

\footnotetext{
2 Termo usado por Angotti (2006).

${ }^{3}$ Cabe o destaque de que devido a terminologia existente para designar os profissionais que atuam diretamente junto à criança pequena em instituições educacionais, até mesmo como forma de hierarquizar salários e tarefas, neste trabalho serão utilizados os termos profissional da educação infantil, educador(a) e professor(a) como sinônimos, sem a pretensão de diferenciar cargos ou funções, pois entende-se que todos devem ter formação específica mínima para o desempenho de tal atividade.
} 
hoje parece ser natural - mulheres associadas à atividade docente - foi alvo de discussões polêmicas, pois havia os que acreditavam que as mulheres eram naturalmente despreparadas para o exercício de tal função. De acordo com Louro $\left(1997\right.$, online $\left.^{t}\right)$ : “[p]ara alguns parecia uma completa insensatez entregar às mulheres usualmente despreparadas, portadoras de cérebros "pouco desenvolvidos" pelo seu "desuso" a educação das crianças" (grifos no original). Mas, vozes contrárias defendiam que as mulheres tinham "por natureza" as habilidades para lidar com crianças, sendo mais adequado atribuir à elas a educação dos pequenos ${ }^{5} \mathrm{e}$ que tal atividade não subverteria sua função e destino primordial que era a maternidade.

Evidenciam-se novamente elementos históricos da herança atual de dominação e desvalorização das ações femininas no âmbito da docência (e fora dela), pois é dentro do cenário descrito que se construiu para a mulher,

[...] uma concepção de trabalho fora de casa como ocupação transitória, a qual deveria ser abandonada sempre que se impusesse a verdadeira missão feminina de esposa e mãe. $O$ trabalho fora seria aceitável para as moças solteiras até o momento do casamento, ou para [...] as solteironas e viúvas. [...] esse caráter provisório ou transitório do trabalho também acabaria contribuindo para que os salários se mantivessem baixos. Afinal o sustento da família cabia ao homem [...] Dizia-se, ainda, que o magistério era próprio para as mulheres porque era um trabalho de "um só turno", o que permitia que elas atendessem suas "obrigações domésticas” (LOURO, 1997, online, grifos no original).

Em outra perspectiva, Barbosa (2011, p. 386) salienta que as profissionais de escolas maternais e jardins da infância foram, até meados do século XX, sempre comparadas à figura e funções maternas de proteção e cuidados; e, ainda,

As características de mãe, enfermeira, professora e assistente social deveriam, dessa ótica, possibilitar um trabalho efetivo de "jardineira", termo utilizado em várias regiões do Brasil. Essa denominação, inspirada na teoria froebeliana, já acentuava a atitude esperada: proporcionar recursos e situações para que as crianças crescessem e se desenvolvessem naturalmente.

Barbosa (2011) afirma ainda que a formação profissional era oferecida em escolas normais ou institutos de educação, em cursos intensivos, estágios e palestras, cujas orientações pedagógicas seguiam as tendências teóricas do momento histórico, com destaque para as concepções de educação nova e liberal ${ }^{6} \mathrm{e}$ educação sanitária de forma indiscriminada, quer seja para atuação na escola primária ou nos jardins de infância. Tal exigência na formação não era meramente por razões pedagógicas, pois grande parte das professoras de crianças pequenas pertencia às classes média e alta, que assumiram a função de maternagem ${ }^{7}$, tida socialmente como nobre e benevolente, e ainda, por ser este o trabalho aceitável para a mulher. No entanto, as exigências de formação e qualificação “[...] não eram pensadas para educadoras de creches ou outras instituições para o atendimento de crianças pobres, cujas mães - solteiras, abandonadas, viúvas, pobres - eram obrigadas a assumir trabalhos fora do ambiente doméstico" (BARBOSA, 2011, p. 387).

É preciso então destacar e reconhecer a intencionalidade que marca a atuação profissional do

\footnotetext{
${ }^{4}$ Apesar de o texto original ser uma publicação impressa, só tive acesso a uma versão digitalizada que não mostrava a paginação. ${ }^{5}$ Tal ideia é ratificada cientificamente pelos escritos de Froebel, para quem as mulheres eram naturalmente dotadas de todos os pré-requisitos necessários para a realização da educação. Sobre esta questão, ver mais em ARCE, A. Friederich Froebel: o pedagogo do jardim da infância. Petrópolis: Vozes, 1996.

6 Os autores de referência desta época foram Pestalozzi, Froebel, Montessori, Decroly, Ferrière, Claparède, Kilpatrick, Dewey, entre outros. Sobre os autores em questão e sua influência na Educação infantil brasileira ver mais em Oliveira-Formosinho, Kishimoto, Pinazza (2005) e Pinazza (2005) entre outros.

7 Prática relacionada aos cuidados afetuosos direcionados ás crianças pequenas, tipicamente vinculados as ações maternais.
} 
docente que atua junto a crianças bem pequenas, uma vez que é necessário, na atuação direta com elas, no desempenho da função educativa no interior das instituições de educação coletiva, uma aproximação, mas também um distanciamento do cuidar materno (este que é realizado de forma instintiva), dadas as especificidades e multiplicidade de aspectos imbricados na tarefa. Em outros termos, ao mesmo tempo em que se aproxima, o papel docente se afasta do de "mãe" ao articular em outro nível as dimensões de cuidado e de educação que marcam as singulares necessidades desta etapa da vida da criança. Esta aproximação e distanciamento se configuram em uma ação constante na prática da educação infantil e elemento básico na constituição da identidade de seus profissionais, uma vez que ao integrar outros papéis, sua efetivação está envolta em inúmeras complexidades (RODRIGUES, 2008, 2013, 2014). Tratase então de "[...] uma profissão que guarda suas especificidades, mas cujos contornos nem sempre são visíveis, reconhecidos e valorizados" (HADDAD, 2013, p. 343).

Agregada a estas questões há também a já mencionada tensão histórica entre assistência e educação, que ronda até os dias atuais as práticas da educação da primeira infância, provocando a hierarquização das tarefas, a cisão na atribuição dos fazeres e a quase unanimemente de práticas que não efetivam o cuidar e educar indissociados contrariamente ao que propõem as Diretrizes Curriculares Nacionais para a Educação Infantil (BRASIL, 2010).

Angotti (2006, p. 94), problematizando esse cenário, aponta de forma explicativa que, procurando se desvincular da maternagem,

[...] as professoras desconsideram as práticas relativas aos cuidados físicos e focalizam seu trabalho naquilo que acreditam ser o "educar", pois só educando, na perspectiva "escolarizante" do termo, as professoras se reconhecem como profissionais do magistério e acreditam ficar isentas de serem vistas como babás ou mães (grifos no original).

Em outra direção, Cunha e Carvalho (2002, p. 4) ponderam que perceber as profissionais da creche como responsáveis pelos cuidados básicos da criança pequena, para qual a sensibilidade afetiva positiva é atributo valorizado, “[...] tem contribuído para o pequeno investimento, até então empreendido na formação docente destas profissionais"; pois “[...] se o que define uma boa educadora de creche são características que não se referem à aquisição de conhecimentos acessíveis, apenas, através de formação acadêmica, não há porque insistir nesta”.

Como professora supervisora de estágio, que faz acompanhamento dos acadêmicos in loco, pude presenciar afirmações do tipo: "A gente faz um trabalho afetivo aqui, tenta criar um vínculo com as crianças, e vocês vem aqui com estas ideias e querem desmanchar o que nós fazemos", referindo-se especificamente a forma de tratamento que elas próprias pedem para as crianças usarem, quer seja, as chamarem de "Tia". Fica evidente (e o que é pior, atual), a denúncia de Cerisara (2002, p. 64), de que "[...] há uma domesticidade nas relações com traços fortes de emotividade, as práticas junto às crianças parecem não guardar traços de racionalidade e objetividade [...]”; a mesma autora afirma ainda que nas instituições de educação infantil, lamentavelmente a meu ver, o que existe é "[...] um universo onde estão presentes práticas femininas domésticas e ausentes práticas femininas profissionais"8. De outro modo,

8 (Ibidem, p. 64). 
quando há a iniciativa de intervenção para que se reconheçam como profissionais, de uma forma bem simples, como serem chamadas de professoras pelas crianças, há o estranhamento e a rejeição.

Recusar o rótulo de tia não significa diminuir ou menosprezar o papel social da tia, como de igual maneira aceitá-lo não traduz valoração; a recusa significa assumir algo que é fundamental à atuação docente: "[...] sua responsabilidade profissional de que faz parte a exigência política por sua formação permanente" (FREIRE, 1993b, p. 11). Parece-me nítido o fato de que as profissionais não têm clareza da real interferência de suas atitudes, do alcance a curto e longo prazo de suas ações, que todas elas são educativas de certa maneira, formando ou deformando sua imagem, bem como os processos de constituição dos sujeitos infantis que estão sob seus cuidados. Há percepções, ou crenças, que transitam no interior das instituições e que são reproduzidas, reforçadas e transmitidas às novas "gerações" de profissionais irrefletidamente...

Freire (1993b, p. 10-11) já esclareceu com maestria que:

A professora pode ter sobrinhos e por isso é tia da mesma forma que qualquer tia pode ensinar, pode ser professora, por isso trabalhar com alunos. Isso não significa, porém, que a tarefa de ensinar transforme a professora em tia de seus alunos da mesma forma como uma tia qualquer não se converte em professora de seus sobrinhos só por ser tia deles. Ensinar é profissão que envolve certa tarefa, certa militância, certa especificidade no seu cumprimento enquanto ser tia é viver uma relação de parentesco. Ser professor implica assumir uma profissão enquanto não se é tia por profissão (grifos no original)

A questão que se faz é: em que medida não são as próprias profissionais que perpetuam práticas e discursos amadores e domésticos? Neste sentido, qual o papel da formação neste quadro? Não surtem efeitos as diferentes propostas de formação - inicial, continuada e em serviço? Por qual razão? A preocupação se intensifica ao ter em mente que alguns estudos realizados, com objetivo de verificar a interferência de cursos de formação inicial na constituição identitária da profissão docente para a Educação Infantil, demonstraram que estes têm contribuído de forma insuficiente para mudar algumas ideias e préconcepções fundantes da prática docente dos estudantes em processo e ao final da formação inicial9.

Tais considerações apontam para o debate com mais afinco sobre a formação mínima necessária aos profissionais da creche - a profissionalidade, bem como sua profissionalização. Estas questões são pertinentes na medida em que a problematização da especificidade e qualidade da educação infantil (creche e também a pré-escola) está direta e intrinsecamente atrelada à discussão das diversas modalidades de formação (inicial, continuada e em serviço) dos profissionais que atuam nesse nível de ensino, independente da nomenclatura que lhes dê (professores, educadores, atendentes, auxiliares, entre outros), tendo em vista que a proficiência da atuação destes profissionais é um dos determinantes no nível de qualidade dos programas de educação de crianças pequenas (RODRIGUES, 2014).

É importante pontuar que a questão da formação e qualificação do profissional docente para atuação na creche foi e continua sendo pauta de intensos debates e reflexões, o que de certa forma indica que ainda há passos importantes a serem dados no sentido de instituir de forma definitiva que profissional

9 Sobre a questão ver resultados de duas pesquisas realizadas no âmbito do GPDFIRS - FCT/Unesp: "As representações construídas por estudantes do curso de Pedagogia sobre profissão docente e a especificidade do trabalho pedagógico na Educação Infantil (2009-2013) e "Estudo sobre formação inicial de professores para infância (2011-2014)" apresentados respectivamente nos textos: Guimarães, Rodrigues e Piffer (2013) e Souza, Rodrigues e Gomes (2015). 
e qual o perfil necessário para atuação qualificada e especializada em instituições de atendimento educacional coletivas que deem conta de atender às necessidades singulares da pequena infância.

\title{
O cenário brasileiro da formação para docência na educação infantil
}

A Educação Infantil no Brasil ganha destaque no cenário nacional a partir da promulgação da Carta Magna de 1988 que prevê a educação em creche e pré-escolas como um dos direitos inalienáveis a ser oferecido pelo Estado a todas as crianças sem distinção (BRASIL, 1988). É a partir deste marco que creches e pré-escolas iniciam o processo de construção de uma nova identidade que, até então, era fortemente marcada por discrepâncias relativas à classe social à qual pertenciam as crianças atendidas.

De igual maneira, a formação dos profissionais para atuar nesse nível de ensino passa a ser objeto de discussão, e impulsiona a realização de debates, reflexões e estudos como o material organizado por Campos, Rosemberg e Viana (1992), cujo conjunto já discutia e apontava a necessidade e importância de se profissionalizar os sujeitos para atuarem na educação infantil, tendo em vista o recém conquistado direito da criança às creches e pré-escolas; considera-se esta, entre outras iniciativas, de extrema relevância, tendo em vista que nesta época “[o] esquema 'sopão e banho' não exigia profissionais especializados e, muitas vezes, os únicos requisitos necessários eram gostar de crianças e saber cuidá-las fisicamente" (ORTIZ, 2007, p. 11, destaque no original).

Com relação à profissionalização, Imbernón (2002) a define como o processo socializador e de aquisição de características específicas da atividade profissional, acentuando as ações que marcam o tipo do fazer e do ser na profissão e a importância e necessidade de sua valorização pela sociedade e pelo grupo que compõe determinada categoria profissional. Neste sentido, tem-se a afirmação de Kramer (2005a, p. 224) de que: “[...] a formação é necessária não apenas para aprimorar a ação profissional ou melhorar a prática pedagógica. A formação é direito de todos os professores, é conquista e direito da população, por uma escola pública de qualidade".

Cabe, então, esclarecer que ao me referir à profissionalização, tomo-a como processo que abarca tanto o desenvolvimento profissional como a construção de uma identidade específica, que está relacionada tanto a uma posição política e social dos sujeitos que se inserem na docência, quanto a políticas públicas que viabilizem o reconhecimento social da profissão - em termos de garantias de espaço de formação, carreira, condições materiais de trabalho etc. (SHIROMA; EVANGELISTA, 2010). Em complemento, Kramer (2005b, p. 8), aponta que,

\begin{abstract}
Profissionalizar não é só qualificar o professor, mas também possibilitar que ele seja inserido numa condição de desenvolvimento, em que essa formação continuada reverta, a longo prazo, numa carreira - não só para ensinar melhor, mas também para que possa viver melhor como cidadão, como indivíduo e como profissional.
\end{abstract}

Trata-se, assim, da busca de integração de saberes - teóricos, da prática cotidiana e emergentes cujo processo "[...] não é apenas individual, mas coletivo e institucionalizado" (OLIVEIRA; FERREIRA; BASTOS, 2011, p. 17). Nesta perspectiva, o desenvolvimento profissional docente é percebido como processo complexo e diacrônico, e, como tal, abarca um variado conjunto de experiências e aprendizagens 
em diferentes momentos e espaços formativos, não sendo desta forma um ato mecânico de aplicação de técnicas ou transposição direta de conhecimentos acumulados em um momento pontual da formação ${ }^{10}$.

O movimento para repensar a função e formação dos profissionais que devem cuidar e educar em espaços coletivos teve sua efervescência entre as décadas 1980 e 1990, sendo o primeiro material oficial produzido no ano de 1994, quer seja o documento intitulado "Por uma política de formação do profissional de educação infantil”"11 - ou 'Caderno carinhas rosa' como ficou popularmente conhecido -, fruto do Encontro Técnico sobre a Política de Formação do Profissional de Educação Infantil realizado no mesmo ano em Belo Horizonte (LANTER, 1999). Ganhou então maior espaço de debate e inclusão no discurso oficial a questão da formação adequada dos chamados 'recursos humanos' para a Educação Infantil. Coordenadora Geral da Educação Infantil junto ao Ministério de Educação e Cultura (MEC) na época, Barreto (1994, p. 11) declarou que:

A formação do professor é reconhecidamente um dos fatores mais importantes para a promoção de padrões de qualidade adequados na educação, qualquer que seja o grau ou modalidade. No caso da educação da criança menor, vários estudos internacionais têm apontado que a capacitação específica do profissional é uma das variáveis que maior impacto causam sobre a qualidade do atendimento [...]

Essa recém conquistada importância também foi evidenciada em outro documento/'caderno carinhas', o "Política Nacional de Educação Infantil”, que traz a afirmação de que: “[...] o adulto que atua, seja em creche, seja na pré-escola, deve ser reconhecido como profissional e a ele devem ser garantidas condições de trabalho, plano de carreira, salário e formação continuada condizentes com o papel que exerce “(BRASIL, 1994, p. 15).

No entanto, em termos de reconhecimento legal, a regulamentação da questão só ocorre no ano de 1996, com a promulgação da LDB no. 9.394, que define, além da inclusão da Educação Infantil como parte da educação básica, também que "[a] formação de docentes para atuar na educação básica far-se-á em nível superior, em curso de licenciatura, de graduação plena, em universidades e institutos superiores de educação [...]" (BRASIL, 1996, Art. 62). Tem-se então um quadro em que são criadas condições para que os profissionais que atuam em creches e pré-escolas detenham os mesmos direitos e deveres dos profissionais docentes vinculados a outros níveis de ensino.

É importante que se tenha em mente de forma clara que equiparar direitos não deve, entretanto, remeter a homogeneização de funções entre os profissionais de diferentes níveis de ensino, pois o dia a dia do Ensino Fundamental não é caracterizado pela mesma dinâmica da Educação Infantil. Se de um lado é desejável identificar o professor como o profissional responsável pela docência na Educação Infantil, não é razoável nomear as crianças como alunos, especialmente os bebês, visto que a dinâmica de interação entre adultos e crianças é mais voltada para crescimento/desenvolvimento/aprendizagens do que para

10 (Ibidem).

$11 \mathrm{Na}$ década de 1990 a Coordenadoria Geral da Educação Infantil (COEDI/MEC) elaborou, com a ampla participação de diferentes entidades e segmentos sociais vinculados a Educação Infantil, diversos documentos com fins de subsidiar a implantação de uma Educação Infantil de qualidade no país. Foram lançados 6 cadernos, a saber: "Política de Educação Infantil" (1993): "Educação infantil no Brasil: situação atual" (1994); "Por uma política de formação do profissional de Educação Infantil" (1994); "Critérios para um atendimento em creches e pré-escolas que respeite os direitos fundamentais das crianças (1995) - este reeditado em 2009; "Proposta pedagógica e currículo para Educação Infantil: um diagnóstico e a construção de uma metodologia de análise" (1996); e, "Subsídios para elaboração de diretrizes e normas para a Educação Infantil (1998). Este material ficou conhecido como cadernos carinhas devido a ilustração da capa que trazia o desenho de rostos de crianças de diferentes aspectos físicos, sendo cada volume de uma cor. Tal material encontra-se disponível no endereço: http://dominiopublico.mec.gov.br. 
ensino/aprendizagens de conteúdos escolares (MACHADO, 1999).

Machado (1999) ainda aponta que reivindicar formação específica para atuar na Educação Infantil, especialmente para os profissionais leigos que já estavam em atuação ${ }^{12}$, significa a admissão de que para desempenhar a função docente, de forma adequada, nesta área, é preciso deter conhecimentos peculiares, delimitando, assim, o que é específico e necessário para o trabalho educativo com a pequena infância.

Nascimento (1999, p. 101) pontuava que, “[...] por lei, a Educação Infantil é um nível de ensino e isto traz consequências para o perfil do profissional que atua neste campo". Tendo em mente que "[um]a proposta pedagógica e curricular se efetiva [...] através de atividades realizadas por crianças e adultos em interação [...] espera-se que os adultos facilitem e promovam os processos de interação ativa da criança com pessoas e as coisas [...]” (GUIMARÃES; GARMS, 2013, p. 20), o que implica a ação intencional de adultos com formação profissional, pois "[n]ao se pode aceitar amadorismo num trabalho cujo fim é a formação de pessoas", como afirma categórica e sapientemente Angotti (2006, p. 102).

Ademais, ainda sobre a exigência de formação inicial mínima, o que poderia ser considerado um grande avanço não é tanto assim, pois o já mencionado artigo 62 da LDB aponta que pode ser “[...] admitida, como formação mínima para o exercício do magistério na Educação Infantil e nas quatro primeiras séries do ensino fundamental, a oferecida em nível médio, na modalidade normal” (BRASIL, 1996).

Embora o texto legal preconize a admissão da formação mínima em nível médio e tenham ocorrido algumas iniciativas de formação neste nível ${ }^{13}$, em grande medida, para atender à diversidade e adversidades do território brasileiro, há um consenso entre pesquisadores, defensores e militantes da Educação Infantil sobre a importância (e necessidade) da formação profissional acontecer em nível superior. No entanto, apesar deste ponto inquietante, é necessário destacar que a nova legislação deixa claro que serão docentesos(as) profissionais que devem atuar junto às crianças pequenas, garantindo assim, em tese, uma certa especificidade na formação inicial e na prática pedagógica.

Amorim e Dias (2013) denunciam que a formação dos profissionais que atuam em creches e pré-escolas sempre foi precária; entretanto, é possível afirmar que com a LDB institucionaliza-se a necessidade de formação docente inicial, e parcialmente é contemplada a questão ao definir que os profissionais tivessem ao menos uma formação básica específica para a docência.

Em contraponto, Kishimoto (2004) já afirmava que a proposta e a aceitação da formação em nível médio colaboram para com a desprofissionalização, em específico dos profissionais de creche, pois em muitos contextos surgiram propostas de se criar duas carreiras na educação infantil - uma para atuação na creche, com aceitação da formação mínima em nível médio, e outra, com formação em nível superior, para as unidades de pré-escola.

Tendo em vista a perspectiva de que a profissionalidade envolve além de outros atributos, o

\footnotetext{
12 Conforme as disposições transitórias da LDB, o $\S 4^{\circ}$ do artigo 87, determina que até o final da década da Educação todos os profissionais deverão ter a formação mínima e específica.

${ }^{13}$ Neste bojo, de aceitação de formação em nível médio e necessidade de adequação da formação mínima dos profissionais que já estavam na Educação Infantil prevista na nova LDB, é lançado em 2005 o Proinfantil - curso na modalidade normal (em nível médio), realizado de forma semipresencial, direcionado exclusivamente aos profissionais atuantes na educação infantil (creches e pré-escolas) das redes públicas (municipal e estadual) e privadas (filantrópicas, confessionais, etc.), com o objetivo basilar de habilitar em magistério os profissionais em exercício para atender os preceitos da legislação vigente e elevar a qualidade das práticas pedagógicas. Sobre esta questão ver mais em Barbosa (2011).
} 
reconhecimento social e a pertença a um corpo coletivo (ROLDÃO, 2005), tais iniciativas configuram um contrassenso, pois a constituição da profissionalidade docente é um processo instável, sempre em construção, surgindo do próprio ato do trabalho, num movimento de reprofissionalização constante (LUDKE; BOING, 2010); bem como um desrespeito uma vez que a Educação Infantil abarca as duas dimensões (creche e pré-escola) e a qualidade da ação pedagógica deve ser garantida em ambas.

Sobre esta questão Craidy (s/d, p. 4) afirma que:

Outro desafio presente entre os educadores na educação infantil é a persistência da figura do monitor, ou professor auxiliar, ou pajem, crecheira, etc. Essa figura parece como forma de burlar a exigência mínima de formação, não porque essa não seja desejada ou que a dificuldade não está em formar o educador infantil, mas em pagá-lo com o salário que corresponde ao de um educador habilitado.

Souza, Rodrigues e Gomes (2014) lembram que as discussões que tratam da formação dos professores para a Educação Infantil precisam considerar duas questões que permitem entender o quadro atual e propor efetivas ações; são elas: 1. a (relativamente) recente incorporação da Educação Infantil como primeira etapa da educação básica, e consequente ampliação de suas funções em caráter legal; pois embora ela assuma novos rumos como etapa primordial de favorecimento do desenvolvimento integral do ser humano, ainda é percebida em alguns segmentos sociais com caráter assistencialista; 2. a distância (ou falta de diálogo ainda existente) entre processo de formação inicial dos professores (em termos de conteúdos e práticas específicos) e a realidade encontrada no cotidiano das instituições educativas. Acrescentaria, ainda, uma terceira questão: a falta de sistematização dos saberes específicos construídos para o trabalho pedagógico direcionado a primeira infância.

Rocha e Strenzel (2002) apontam o fato de haver poucos debates sobre saberes dos professores e a condição de ser professor de Educação Infantil por estarem estes ainda em construção; mais de uma década passada, apesar de inúmeros esforços, reflexões e debates, ainda há questões polêmicas e de certa forma indefinidas quando se faz relação entre o que se vem produzindo e as adequações necessárias efetivadas na prática cotidiana das instituições.

Nessa direção, Oliveira (2007a, p. 15) afirma que “[já] existe um conjunto expressivo de saberes que apontam algumas condições necessárias ao estabelecimento de interações mais colaborativas e prolongadas pelas crianças com parceiros de idade, em vez de curtos e/ou disruptivos períodos de interação, em ambientes de educação coletiva"; mas estes saberes não necessariamente foram (estão) sendo socializados nos espaços de formação inicial.

Tem-se, somente dez anos depois da aprovação da LDB, com a aprovação das novas Diretrizes Curriculares Nacionais dos Cursos de Pedagogia (BRASIL, 2006), o reconhecimento do legítimo espaço de formação de professores/as para/da Educação Infantil, exigindo a oferta de conteúdos teóricos específicos e estágio curricular em creches e pré-escolas.

Pimenta (1999, p. 15) já discutia que se espera dos cursos de licenciatura que,

[...] desenvolva nos alunos conhecimentos e habilidades, atitudes e valores que thes possibilitem permanentemente irem construindo seus saberes-fazeres docentes a partir das necessidades e desafios que o ensino como prática social lhes coloca no cotidiano. [...] que mobilize conhecimentos da teoria da educação e da didática necessários à compreensão do ensino como realidade social, e que desenvolva neles a capacidade de 
investigar a própria atividade para, a partir dela, construírem e transformarem seus saberes-fazeres docentes, num processo contínuo de construção de suas identidades como professores.

$\mathrm{Na}$ contramão dessas ideias, a mesma autora denunciava um quadro que ainda se faz presente no cenário da formação inicial para a docência, de que “[...] os cursos de formação, ao desenvolverem um currículo formal com conteúdos e atividades distanciados da realidade das escolas, [...] não dá conta de captar as contradições presentes na prática social de educar, pouco têm contribuído para gestar uma nova identidade do profissional docente" (PIMENTA, 1999, p. 16).

Complementarmente Kishimoto (2004) já denunciava que a formação para a docência, tradicionalmente, se dá em centros de formação que não mantém os vínculos necessários com os espaços de atuação profissional; o que, por consequência, inviabiliza as necessárias mudanças na prática pedagógica; de acordo com a autora, “[a]s inovações duradouras exigem uma formação centrada na unidade infantil e na organização inteira"14.

Conforme apontam Amorim e Dias (2013), a valorização dos profissionais docentes para atuarem junto a pequena infância, pautada na (re)construção de sua identidade e o seu reconhecimento social e profissional impõe aos cursos de formação inicial o desafio de superar as ideias arraigadas no senso comum de que "dom, vocação, maternagem e afetividade feminina” são as marcas, ou exigências básicas, para a prática pedagógica em instituições de educação infantil.

Guimarães e Garms (2013, p. 32) afirmam que propostas de formação para a docência,

[...] devem ser concebidas como prática social de reflexão contínua e coerente com a prática que se almeja implantar; um dos caminhos indicados para o professor ser protagonista de seu processo formativo. Faz-se essencial definir que a formação é necessária não apenas para aperfeiçoar a ação profissional e a prática correspondente, mas é direito de todos os professores.

Ainda nessa linha de pensamento, Gomes (2009) aponta que na congregação de saberes e fazeres é preciso ter a habilidade de reflexão diária, para assim, atuar de forma consciente na educação das crianças bem pequenas; em suas palavras, a atividade docente neste nível de ensino:

[...] requer saberes e conhecimentos científicos, pedagógicos, educacionais, sensibilidade, indagação teórica e criatividade para encarar as situações ambíguas, incertas, conflituosas, e por vezes, violentas, presentes nos contextos escolares e não escolares. É da natureza da atividade docente proceder à mediação reflexiva e crítica entre transformações sociais concretas e a formação humana dos alunos, questionando o modo de pensar, sentir, agir e de produzir e compartilhar conhecimentos (GOMES, 2009, p. 15).

Micarello (2005, p. 144, grifo no original) por sua vez afirma que "[...] "o poder transformador" da teoria está diretamente ligado à possibilidade de os indivíduos fazerem uma reflexão crítica, tanto sobre os pressupostos teóricos quanto sobre os desafios que se colocam na prática"; tal apontamento induz ao compromisso das propostas de formação profissional (inicial, continuada e em serviço) de organizar esforços para superar o discurso presente no repertório dos profissionais docentes de que "a teoria na prática é outra", fruto da falta de autonomia intelectual.

14 (Ibidem, p. 329) 
A questão inquietadora é como formar o profissional reflexivo, crítico e capaz de construir sua autonomia intelectual, se em todos os níveis de ensino o que caracteriza mais fortemente a "escola" é o processo de ensino pautado na aula fria, monótona e expositiva, em que o aprendiz é solicitado apenas a "engolir passivamente" as informações que são mecanicamente oferecidas para em um determinado momento reproduzi-las de forma acrítica; Freire (1996, p. 22) já afirmou que "[...] ensinar não é transferir conhecimento, mas criar possibilidades para sua produção ou a sua construção" (destaque no original).

Acredito que a máxima socrática de "parir ideias"15 e permitir que os aprendizes se sintam capazes de encontrar as respostas por si mesmos como forma por excelência de efetivar o ensinoaprendizagem, ou ensinagem ${ }^{16}$ num sentido mais atual, de fato ofereceria condições para a formação do profissional reflexivo e crítico. Além disto, seria necessário criar condições educacionais para que a aprendizagem seja entendida como processo que faz parte da vida - ao contrário do slogan de que se aprende/ensina para a vida - e desta maneira, se dá ao longo de toda vida; não se deve aprender por aprender, por obrigação, mas para, de forma progressiva (e sem fim), construir a autonomia e o espírito crítico e criativo que permite a compreensão ampla do mundo e da relação com o entorno.

Nessa direção Freire (1996, p. 45) afirmou que "[n]ehuma formação docente verdadeira pode fazerse alheada, de um lado, do exercício da criticidade que implica a promoção da curiosidade ingênua à curiosidade epistemológica, e de outro, sem o reconhecimento do valor das emoções, da sensibilidade, da afetividade [...]"; tais questões levariam a profissão à tomada de consciência acerca da amplitude do seu fazer profissional. Pimenta e Lima (2012) reforçam este entendimento afirmando que faz parte da natureza da docência realizar a mediação crítica e reflexiva entre os meandros da realidade social e a formação humana dos aprendizes em situação escolar, que se configura então num saber imprescindível para o exercício pleno da profissão.

O termo "crítica/crítico", conforme definição do próprio Freire (1996), traz em seu bojo elementos como consciência, curiosidade, postura, atitude, leitura, pesquisa, esforço, sujeito, pensamento, compreensão, conscientização, auto inserção, entre outros. Destarte, penso ser importante que no processo de formação para atuação profissional na Educação Infantil, sejam contempladas (e até priorizadas) discussões e práticas que auxiliem a(o)s futuras educadora(e)s refletirem sobre as concepções de criança, infância, aprendizagem, desenvolvimento, educação, ensino, papéis e responsabilidade social do professor que adotam e quais seriam as desejáveis, como forma de viabilizar a construção de uma postura autônoma, verdadeiramente crítica e reflexiva na organização de sua ação pedagógica nas instituições de educação coletiva.

Tal afirmação parece de uma obviedade ao mesmo tempo ingênua e ofensiva em se tratando do que deveriam ser os objetivos fundantes dos cursos de licenciatura; no entanto, em muitos cursos de formação docente, estas questões não ocupam a centralidade das reflexões propostas; questões mais amplas que visam uma formação mais generalista, pautada no discurso da necessidade de formação do profissional (e não o professor) polivalente ocupam a maior parte dos currículos e conteúdos das

${ }^{15}$ Esta é uma referência à maiêutica, método de ensino empregado pelo filósofo Sócrates que consiste basicamente na realização de sucessivos questionamentos que induzem o interlocutor, através do diálogo reflexivo, descobrir as respostas, ou "suas verdades" na conceituação geral de um fato ou objeto.

16 Termo cunhado por Anastasiou (1998) para designar uma situação de ensino do qual decorre necessariamente uma aprendizagem a partir do estabelecimento de uma parceria entre professor e aprendiz, pensada inicialmente em situações do Ensino Superior, mas utilizada aqui analogamente como aplicável a qualquer nível de ensino. 
disciplinas dos cursos. É o caso do curso de Pedagogia em que atuo como professora, que apesar de ter quase 50 anos de existência, somente nos últimos anos incluiu em sua pauta de discussões e preocupações (estrutura curricular e reflexões paralelas nos espaços de pesquisa e extensão) a questão da formação de professores (para todos os níveis).

Reafirma-se, então, que o processo de formação profissional precisa favorecer a construção e elaboração de conhecimentos de diversas naturezas (legais, práticos e teóricos das mais variadas áreas), para que na ação cotidiana da educação infantil o professor saiba como organizar o ambiente e sua ação voltados à promoção de uma pedagogia que favoreça a efetiva participação das crianças, valorizando e incentivando o exercício da capacidade de comunicação, expressão e representação destas; garantindo, assim, a efetivação de "[...] propostas pedagógico-curriculares com identidade própria, plenas de referenciais teóricos e práticos que traduzam a compreensão da amplitude do respeito aos direitos da criança, seja na creche, seja na pré-escola” (RODRIGUES; GUIMARAES; PIFFER, 2011, p. 291).

Gomes (2009) ainda aponta que o processo de formação para atuação na Educação Infantil deve ser permanente e envolver em sua dinâmica a valorização da identidade e do profissionalismo dos professores, tornando-se assim numa complexa tarefa de aprimoramento da qualidade cotidiana do trabalho. Assim, promover aprendizagens, o desenvolvimento e o bem estar das crianças em instituições de educação coletiva se configura em uma tarefa difícil, complexa e exigente e não se coaduna com uma atitude informal, intuitiva; desta maneira exige para sua efetivação profissionais sintonizados e atentos às necessidades das crianças que sabem o que fazem e por quê o fazem; um fazer intencional, organizado em função da convivência estimulante, cooperativa e rica em experiências; dentro do processo de formação inicial, o estágio docente pode ser entendido como o momento ideal para que se concretizem tais aprendizagens, uma vez que pode ser caracterizado como "tempo e espaço de inúmero encontros".

De acordo com Wallon (1979) a formação dos professores não pode ficar limitada aos livros; deve antes ter como referência inquestionável as experiências pedagógicas que eles próprios podem realizar, no sentido de adaptar as orientações dos manuais às condições reais do espírito e natureza da criança com a qual lida no dia-a-dia. Desta forma, o professor de crianças bem pequenas precisa de uma formação que abarque conhecimentos que ofereçam os alicerces básicos e sólidos para que lhe seja permitido construir, compreender e confrontar ideologias, uma vez que o ambiente educacional é permeado e, muitas vezes, calcado em representações ideológicas.

\section{Últimas considerações}

A profissão docente, de forma geral, é marcada por pré-conceitos e preconceitos que existem há várias décadas, o que consideramos serem inoportunas persistências; no que diz respeito especificamente à atuação, ao exercício profissional junto à crianças pequenas, o quadro é ainda mais desanimador, pois conforme já apontado anteriormente, quanto menor a idade do público atendido, menor a valorização profissional. 
A partir dos anos de 1990, muitas discussões, estudos e documentos foram produzidos com vistas a efetivação de uma Educação Infantil de qualidade; avanços significativos podem ser observados na legislação brasileira, alcançados em virtude de debates e lutas envolvendo diversos movimentos sociais, intelectuais, militantes em prol de um atendimento educacional que promova o bem-estar das crianças. No entanto, ainda que alguns consensos tenham sido estabelecidos, a prática pedagógica cotidiana das instituições ainda não reflete de forma satisfatória as conquistas legais.

Os desafios a serem superados, no que diz respeito à educação das crianças pequeninas, continuam sendo superar a dicotomia entre cuidar e educar, a concepção que identifica as instituições de Educação Infantil como extensão do Ensino Fundamental, bem como a não valorização da docência nesse nível.

Afirma-se, então, que a perspectiva formativa aqui defendida destaca “[...] a importância da criação de oportunidades para os professores questionarem suas crenças e práticas institucionais, localizarem seus pontos de resistência a mudanças, considerando os docentes não como meros consumidores, mas como produtores do conhecimento" (OLIVEIRA; FERREIRA; BARROS, 2011, p. 23).

Assim, toda e qualquer proposta de qualificação de profissionais (futuros ou já em atuação) para trabalhar na Educação Infantil, precisa buscar oferecer a estes condições para a construção e/ou reafirmação de sua identidade profissional, tendo em mente que a superação da histórica desvalorização de sua profissão passa por sua tomada de posição na percepção de que é um profissional que possui um objeto de estudo e uma área de atuação específicos, que precisam ser assumidos e definidos como de extrema relevância social; de outra forma não há como trilhar o efetivo caminho do reconhecimento social e de organização para reivindicação de melhores condições de formação e de trabalho.

Angotti (2006, p. 19), afirma que a profissionalidade dos educadores infantis deve ser fundamentada "[...] na efetivação de um cuidar que promova a educação, e de uma educação que não deixe de cuidar da criança, e de atendê-la em suas necessidades e exigências essenciais desde a sua mais tenra idade [...]”.

Nessa direção Silva e Rossetti-Ferreira (2001) propõem que nos espaços de formação, aos futuros educadores sejam possibilitados: 1- tempos e espaços de socialização, de troca e encontro; 2- um instrumental e conhecimentos que lhes permitam criar e produzir, ligando-se ao mundo; 3- condições para a vivência e inserção na cultura científica; 4- um "caldo cultural" que favoreça sua apropriação dos bens culturais historicamente acumulados; 5-oportunidades para a construção de identidade e autoconceito positivos, promovendo o seu desenvolvimento pessoal e profissional.

Diferentes autores (BONDIOLI; MANTOVANI, 1998; OLIVEIRA, 2007a, 2007b entre outros) destacam a importância de que os cursos de formação inicial para a docência junto às crianças pequenas socializem conhecimentos sobre as características do desenvolvimento infantil, estruturação do espaço físico e da rotina diária, materiais a serem utilizados e estratégias de interação com os pequenos, entre outras questões favoreçam e permitam as trocas de experiências entre as crianças e também entre as crianças e os adultos, com vistas à aprendizagem e um adequado desenvolvimento global.

Por outro lado, a complexidade da docência, especialmente na Educação Infantil, evidencia que apenas os conhecimentos advindos dos cursos de formação inicial não oferecem respostas aos dilemas 
encontrados no cotidiano; decorre desse fato a necessidade da constante reconstrução de saberes e práticas, via cursos de formação continuada, bem como das trocas cotidianas entre os pares como profícuo caminho para alcançar necessárias mudanças na formação dos profissionais e por consequência nas práticas pedagógicas no interior de creches e pré-escolas.

Cabe finalizar apontando que Mantovani e Perani (1999) já discutiam que a docência na educação de crianças pequenas é "uma profissão a ser inventada"; quase duas décadas se passaram desde que este registro foi realizado e penso que continuamos na tarefa de "arquitetá-la"...

\section{Referências}

AMORIM, A. L. N.; DIAS, A. A. Formação do professor de educação infantil: políticas e processos. Revista Educacão. PUC-Campinas, Campinas, n. 18, v. 1, p. 37-45, jan./abr., 2013. Disponível em: http://periodicos.puc-campinas.edu.br/seer/index.php/reveducacao/article/view/1896/1724. Acesso em: 15 ago. 2014.

ANGOTTI, M. Educação Infantil: para que, para quem e por quê.In: ANGOTTI, M. (Org.). Educação Infantil: para que, para quem e por quê?Campinas: Alínea, 2006. p. 15-32.

AQUINO, L. L. Professor de educação infantil. In: OLIVEIRA, D. A.; DUARTE, A. M. C.; VIEIRA, L. M. F. Dicionário: trabalho, profissão e condição docente. Belo Horizonte: UFMG/Faculdade de Educação, 2010. CDROM. Disponível em: http://www.gestrado.org/?pg=dicionario-verbetes\&id=338. Acesso em: 08 de mai. 2015.

BARBOSA, I. G. O Proinfantil e a formação do professor.Revista Retratos da Escola, Brasília, v. 5, n. 9, p. 385-399, jul./dez. 2011. Disponível em: http://esforce.org.br/index.php/semestral/article/viewFile/20/181. Acesso em: 11 mai. 2014.

BARRETO, A. M. R. F. Por que e para que uma política de formação do profissional de educação infantil? In: BRASIL, Ministério da Educação e do Desporto. Secretaria de Educação Fundamental. Por uma política de formação do profissional de Educação Infantil. Brasília: MEC/SEF/COEDI, 1994. p. 11-15.

BONDIOLI, A.; MANTOVANI, S. Manual de educação infantil de 0 a 3 anos - uma abordagem reflexiva. Trad. Rosana Severiano Di Leone e Alba Olmi. Porto Alegre: Artmed, 1998.

BRASIL. Constituição (1988). Constituição da República Federativa do Brasil:promulgada em 5 de outubro de 1988. Disponível em: http://www.planalto.gov.br/ccivil_03/constituicao/constituicao.htm. Acesso em: 18 fev. 2009. 
BRASIL, Ministério da Educação e do Desporto. Secretaria de Educação Fundamental. Por uma política de formação do profissional de Educação Infantil. Brasília: MEC/SEF/COEDI, 1994.

BRASIL. Lei ñ. 9.394, de 20 de dezembro de 1996. Estabelece as diretrizes e bases da educação nacional. Disponível em: http://www.planalto.gov.br/ccivil_03/leis/19394.htm. Acesso em: 18 fev. 2009.

BRASIL. Conselho Nacional de Educação. Resolução CNE/CP nº. 01/2006. Institui as Diretrizes Curriculares Nacionais para o Curso de Graduação em Pedagogia, licenciatura. 2006. Disponível em: http://portal.mec.gov.br/cne/arquivos/pdf/rcp01 06.pdf. Acesso em: 11 maio 2014.

BRASIL. Ministério da Educação. Secretaria de Educação Básica. Diretriz̧es Curriculares Nacionais para a Educação Infantil. Brasília: MEC/SEB, 2010.

CAMPOS, M. M. A formação de professores para crianças de 0 a 10 anos: modelos em debate. Educaşão e Sociedade, v. 20, n. 68, p. 126-142, 1999. Disponível em: http://www.scielo.br/pdf/es/v20n68/a07v2068.pdf. Acesso em: 5 fev. 2009.

CAMPOS, M. M.; ROSEMBERG, F. VIANA, C. P. A formação do educador de creche: sugestões e propostas curriculares. São Paulo: Fundação Carlos Chagas, 1992.

CERISARA, A. B. Professoras de Educação Infantil: entre o feminino e o profissional. São Paulo: Cortez, 2002.

CORREAA, C. P. Q.; FERNANDES, M. M. S. Formação docente na educação infantil: desafios contemporâneos para a formação permanente. Zero-a-seis, Florianópolis, v. 16, n. 30 p. 275-289, jul.-dez., 2014.

CRAIDY, C. A formação de educadores para a educação infantil: exigências, desafios e realidade. [20--.]

Disponível em:

http://webcache.googleusercontent.com/search?q=cache:atqk 1KeBzQJ:www.grupos.com.br/group/ped 430/Messages.html\%3Faction\%3Ddownload $\% 26 y e a r \% 3 D 08 \% 26$ month $\% 3$ D6\%26id $\% 3$ D 121258296694 7619\%26attach $\% 3$ Dleitura $\% 2520$ complementar $\% 2520-\% 2520$ Carmem $\% 2520$ Craidy.pdf $+\& c d=2 \& h l=p t-$ PT\&ct $=$ clnk\&gl=br. Acesso em 13 set. 2005.

CUNHA, B. B. B.; CARVALHO, L. F. Cuidar de crianças em creches: os conflitos e os desafios de uma profissão em construção. In: REUNIÃO ANUAL DA ANPED. 25, 2002, Caxambu. Anais... Caxambu: Anped, 2002. Disponível em: http://25reuniao.anped.org.br/tp25.htm\#gt7. Acesso em: Acesso em: 15 abr. 2006. 
FREIRE, P. Política e educação. São Paulo: Cortez, 1993a.

FREIRE, P. Professora sim, tia não. Cartas para quem ousa ensinar. São Paulo: Olho dágua, 1993 b.

FREIRE, P. Pedagogia da autonomia: saberes necessários à prática educativa. 44. ed. São Paulo: Paz e Terra, 1996.

GARCIA, M. M. Identidade docente. In: OLIVEIRA, D. A.; DUARTE, A. M. C.; VIEIRA, L. M. F.

Dicionário: trabalho, profissão e condição docente. Belo Horizonte: UFMG/Faculdade de Educação, 2010.

CDROM. Disponível em: http://www.gestrado.org/?pg=dicionario-verbetes\&id=46. Acesso em: 08 de mai. 2015.

GATTI, B. A. Os professores e suas identidades: o desvelamento da heterogeneidade. Cadernos de Pesquisa, Fundação Carlos Chagas: São Paulo, n. 98, p. 85-90, ago./1996.

GOMES, M. O. Formação de professores na Educação Infantil. São Paulo: Cortez, 2009.

GUIMARAES, C. M. et al. O que revelam os estudos brasileiros sobre as práticas de formação de professores para Educação Infantil. In: CONGRESO NACIONAL DE EDUCAÇÃO - EDUCERE. 7, 2009, Curitiba. Anais... Curitiba: PUC/PR, 2009. p. 2.643-2.656.

GUIMARÃES, C. M.; GARMS, G. M. Z. Currículo para a educação e o cuidado da criança de 0 a 5 anos? Revista Educação, PUC-Campinas, Campinas, n. 18, v. 1, p. 19-35, jan./abr., 2013. Disponível em: http://periodicos.puc-campinas.edu.br/seer/index.php/reveducacao/article/view/1895/1723. Acesso em: 10 jan. 2015.

HADDAD, L. Profissionalismo na educação infantil: perspectivas internacionais. Revista Educação Pública, Cuiabá, v. 22, n. 49/1, p. 341-359, maio/ago. 2013.

IMBERNÓN, F. Formação docente e profissional: formar-se para a mudança e a incerteza. 3. ed. São Paulo: Cortez, 2002.

KISHIMOTO, T. M. O sentido da profissionalidade para o educador da infância. In: BARBOSA, R. L. L. (Org.). Trajetórias e perspectivas da formação de educadores. São Paulo: UNESP, 2004. p. 329-345.

KRAMER, S. Profissionais de educação infantil: gestão e formação. São Paulo: Ática, 2005a.

KRAMER, S. Aprendendo com criança a mudar a realidade. Revista Criança, n. 39, p. 5-8, 2005 b. 
LANTER, A. P. A política de formação do profissional de educação infantil: os anos 90 e as diretrizes do MEC diante da questão. In: KRAMER, S. et al. (Org.). Infância e Educação Infantil. Campinas: Papirus, 1999. p. $131-158$.

LOURO, G. L. Mulheres na sala de aula. In: DEL PRIORE, M. (Org.). História das mulheres no Brasil. São Paulo: Contexto, 1997. Disponível em: https://pt.scribd.com/doc/19022210/Mulheres-na-Sala-deAula\#scribd. Acesso em 15 maio 2015.

LUDKE, M.; BOING, L.A. Profissionalidade docente. In: OLIVEIRA, D. A.; DUARTE, A. M. C.; VIEIRA, L. M. F. Dicionário: trabalho, profissão e condição docente. Belo Horizonte: UFMG/Faculdade de Educação, 2010. CDROM. Disponível em: http://www.gestrado.org/?pg=dicionarioverbetes\&id $=345$. Acesso em: 08 maio 2015.

MACHADO, M. L. Criança pequena, educação infantil e formação dos profissionais. Perspectiva.Revista do Centro de Ciências da Educação, Florianópolis, v. 1, n. especial, p. 85-98, jul./dez. 1999.

MANTOVANI, S.; PERANI, R. M. Uma profissão a ser inventada: o educador da primeira infância. Proposições, Campinas, v. 10, n. 1, p. 75-98, mar., 1999. Disponível em: http://www.proposicoes.fe.unicamp.br/proposicoes/textos/28-artigos-mantovanis_etal.pdf. Acesso em: 15 mar. 2010.

MICARELLO, H. Formação de profissionais da Educação Infantil: "sair da teoria e entrar na prática?”. In: KRAMER, S. Profissionais de educaşão infantil: gestão e formação. São Paulo: Ática, 2005. p. 140-155.

NASCIMENTO, M. E. P. Os profissionais da Educação Infantil e a nova Lei de Diretrizes e Bases da Educação Nacional. In: FARIA, A. L. G.; PALHARES, M. S. (Org.). Educação Infantil pós-LDB: rumos e desafios. Campinas: Autores Associados, 1999. p. 99-110.

NOGUEIRA, R, M. S. O trabalho do professor de Educação Infantil. Educação e Fronteiras, Dourados, v. 2, n. 4, p. 95-112, jul./dez. 2008.

NÓVOA, A. Formação de professores e profissão docente. In: NÓVOA, A. (Org.). Os professores e a profissão. Lisboa: Dom Quixote, 1992. p.15-33.

OLIVEIRA, Z. M. R. Educação Infantil: fundamentos e métodos. 3. ed. São Paulo: Cortez, 2007a. 
OLIVEIRA, Z. M. R. Como definir uma pedagogia que oriente o trabalho em creche. RevistaPátio Educação Infantil, ano V, n. 13, p. 14-16, mar./jul. 2007b.

OLIVEIRA, Z. M. R.; FERREIRA, M. V.; BARROS, J. A. B. Formação continuada em educação infantil: a construção de uma agenda de possibilidades. In: GUIMARAES, C. M.; REIS, P. G. R. (Org.). Professores e infâncias: estudos e experiências. Araraquara: Junqueira e Marin, 2011. p. 13-28.

ORTIZ, C. O papel do professor de crianças pequenas. RevistaPátio Educaşão Infantil, ano V, n. 13, p. 10-13, mar./jun. 2007.

OSTETTO, L. E. Articular saberes, qualificar práticas: contribuições da universidade à formação dos profissionais de educação infantil. Perspectiva, Florianópolis, v. 15, p. 11-20, jul./dez. 1997. Disponível em: https://periodicos.ufsc.br/index.php/perspectiva/article/viewFile/10613/10147. Acesso em: 08 fev. 2013.

PIMENTA. S. G.; LIMA, M. S. L. Estágio e docência. 7. ed. São Paulo: Cortez, 2012.

PIMENTA, S. G. Formação de professores: identidade e saberes da docência. In: PIMENTA, S. G. (Org.). Saberes pedagógicos e atividade docente.São Paulo: Cortez, 1999, p. 15-34.

PROENÇA, M. L. A construção de um currículo em ação. RevistaPátio Educaşão Infantil, ano VII, n. 21, p. 14-16, nov./dez. 2009.

ROCHA, E. A. C.; STRENZEL, G. R. Indicadores para a avaliação de contextos educativos em creche: articulando pesquisa pedagógica e formação profissional. In: REUNIÃO ANUAL DA ANPED. 25, 2002, Caxambu. Anais... Caxambu: Anped, 2002. Disponível em:

http://25reuniao.anped.org.br/posteres/eloisaacirescandalrochap07.rtf. Acesso em: 08 fev. 2013.

RODRIGUES, S. A. Expressividade e emoções na primeira infância: um estudo sobre a interação criança-criança na perspectiva walloniana. 2008. 110f. Dissertação (Mestrado em Educação) - Faculdade de Ciências e Tecnologia, Universidade Estadual Paulista, Presidente Prudente, 2008.

RODRIGUES, S. A. Reflexões sobre a organização de práticas educativas no contexto da Educação Infantil.Nuances: estudos sobre Educação. Presidente Prudente, n. 25, v. 01, p. 183-199, jan./abr. 2013.

RODRIGUES, S. A. Ser professor na Educação Infantil: expectativas de estudantes em processo de formação inicial. SEMINÁRIO EDUCAÇÃO 2014, Cuiabá. Anais... Cuiabá: UFMT, 2014. 
RODRIGUES, S. A.; GUIMARAES, C. M.; PIFFER, C. C. G. Representações Sociais sobre criança e ser professora de crianças por alunas dos Cursos de Pedagogia da UFMS e UNESP. Práxis Educativa, Ponta Grossa, v. 6, n. 2, p. 289-301, jul./dez. 2011.

ROLDÃO, M. C. Profissionalidade docente em análise - especificidades do ensino superior e não superior. Revista Nuances: estudos sobre educação. Ano XI, v. 12, n. 13, p. 106-126, jan./dez. 2005.

SHIROMA, E. O.; EVANGELISTA, O. Profissionalização docente. In: OLIVEIRA, D. A.; DUARTE, A. M. C.; VIEIRA, L. M. F. Dicionário: trabalho, profissão e condição docente. Belo Horizonte: UFMG/Faculdade de Educação, 2010. CDROM. Disponível em: http://www.gestrado.org/?pg=dicionario-verbetes\&id=346. Acesso em: 08 de mai. 2015.

SILVA, A. P. S.; ROSSETTI-FERREIRA, M. C. Formação dos profissionais da educaşão infantil: a pessoa no centro da ação. 2001. (texto impresso).

SOUZA, D. B.; RODRIGUES, S. A.; GOMES, A. A. Aprendizagem da docência: o papel do estágio na formação de profissionais da Educação Infantil. In: JORNADA BRASILEIRA DE EDUCAÇÃO E LINGUAGEM E X JORNADA DE EDUCAÇÃO DO MATO GROSSO DO SUL. I, 2014, Campo Grande. Anais online. Campo Grande: UCDB, 2014. p. 1-11.

WALLON, H. A formação psicológica dos mestres. In: WALLON, H. Psicologia e educaşão da criança. Lisboa: Editorial Vega, 1979. p. 343-354. 